\title{
RESEÑA CRÍTICA DEL EMPRESARIO EN EL PENSAMIENTO ECONÓMICO NEOCLÁSICO, KEYNESIANO Y CONTEMPORÁNEO.
}

\author{
Beatriz Pérez Sánchez*, Jaime M. Zurita Campos**.
}

\begin{abstract}
Pérez-Sánchez B., Zurita-Campos J.M.. Reseña crítica del empresario en el pensamiento económico neoclásico, keynesiano y contemporáneo. Hitos de Ciencias Económico Administrativas 2011;17 (49):103-114.
\end{abstract}

\section{RESUMEN}

Objetivo: Abordar los antecedentes del estudio del empresario en la economía neoclásica, keynesiana y contemporánea. En una etapa histórica que nace con la Revolución Industrial, se define al empresario como el propietario del capital; no obstante con la evolución del sistema capitalista esta definición resulta insuficiente.

Material y metodos: Los métodos que se utilizaron fueron el método histórico-crítico, y el método comparativo. El método histórico-crítico, da mayor peso al origen histórico y a las condiciones de surgimiento para establecer la configuración definitiva y las prácticas económicas en la economía neoclásica, keynesiana y contemporánea. Así mismo; el método comparativo nos permite realizar una taxonomía del empresario. Se realiza una investigación bibliográfica de 12 teóricos representantes de estas tres corrientes.

Resultados: El concepto de empresario aparece íntimamente unido al concepto de empresa concebida como realidad socioeconómica. El empresario personaliza la actuación de la empresa siendo la figura representativa que persigue objetivos coherentes con los fines a conseguir por la empresa en un intervalo temporal. teóricos

Conclusiones: Las aportaciones, más que brindar una teoría satisfactoria del empresario, se complementan mutuamente para configurar valores, atributos, comportamientos y habilidades que los empresarios requieren para ser catalogados como tales. Al revisar los aportes, principales ideas y planteamientos de los autores que escribieron sobre los empresarios se encontró que se interesaron por definir: a) quién es un empresario; b) qué hace, es decir cuál es su función. A fines del siglo XIX y con el crecimiento en dimensión de las grandes empresas, comienza en la economía una preocupación por la actividad empresarial como función distinta de la propiedad de la empresa.

\section{Pérez-Sánchez B., Zurita-Campos J.M. Critical review of the entrepreneur in the neoclassic, keynesian and contemporary economics thought. Hitos de Ciencias Económico Administrativas 2011;17 (49):103-114.}

\section{ABSTRACT}

Objetivo: Review the background to study the entrepreneur in the neoclassical, Keynesian, and Contemporary economics. In a historic stage that was born with the Industrial Revolution, the entrepreneur is defined as the owner of the capital; however, with the evolution of the capitalist system this definition is insufficient.

Material and method:The historical-criticism and the comparative method were used. The first one focuses its attention to the historical origins and the conditions of the appearance to establish the definite configuration and the economical practices in the neoclassical, Keynesian and contemporary economics. On the other hand, the comparative method allows us to make the taxonomy of the entrepreneur. A bibliographic research of 12 theoreticians of these three thoughts was performed.

Results: The concept of entrepreneur appears intimately linked to the concept of enterprise conceived as a socioeconomic reality. The entrepreneur personalizes the performance of the company being the representative character that pursues the coherent goals of the company in a temporary interval.

Conclusions: The contributions, more than providing a satisfactory theory of the entrepreneur, are mutually complemented to configure values, attributes, behaviors and abilities that the entrepreneurs require to be catalogued as they are. After reviewing the contributions, main ideas, and approaches of the authors who wrote about the entrepreneurs, it was found that they were interested to define a)who an entrepreneur is; $b$ ) what an entrepreneur does, this is, what his/her function is. At the end of the XIX century and with the growth in dimension of the great enterprises, it starts in the economics a preoccupation for the entrepreneurial activity as a different function of the company property.

Palabras clave: Empresario. Empresa. Actividad

Key words: Entrepreneur. Enterprise. Entrepreneurial empresarial. Historia económica. Teoría económica. activity. Economic History. Economic theory.

DIRECCIÓN PARA RECIBIR CORRESPONDENCIA: Correo electrónico: beatrizperez10@hotmail.com

* Doctora en Economía. Profesora-Investigadora. División Académica de Ciencias Económico Administrativas. Universidad Juárez Autónoma de Tabasco (UJAT).

** Doctor en Ciencias. Profesor-Investigador. Facultad de Economía. Universidad Nacional Autónoma de México.

Fecha de recibido: 9 de septiembre de 2011 Fecha de aceptación: 4 de octubre de 2011. 
A

nalizando la evolución histórica-teórica del empresario, se observa que los orígenes en términos teóricos se inician con la obra de Richard Cantillon, que va desde 1775 hasta finales del siglo XIX. Se ha afirmado que en el desarrollo de la teoría económica se niega la existencia del entrepreneurship, aunque esto no significa que los economistas no hayan discutido algunos aspectos sobre el tema. De hecho Adam Smith y Ricardo no desarrollaron una teoría económica o filosófica sobre el empresario propiamente dicha, aunque sus análisis sentaron las bases principales para los desarrollos teóricos modernos sobre la economía de la empresa. Los primeros estudios como tal sobre el empresario hay que situarlos a finales del siglo XIX y principios del XX, se realizaron en el contexto de la teoría de la utilidad marginal, que servirá de base para un posterior desarrollo de una teoría empresarial. Es en el pensamiento neoclásico y contemporáneo donde se encuentran más aportes a la discusión de su función dentro del proceso productivo.

\section{Evolución teórica-histórica del empresario.}

Se estudiaron las principales ideas y planteamientos de los economistas neoclásicos cuyo origen se remonta hacia fines del siglo XIX, es el cuerpo de pensamiento económico más generalmente aceptado en el mundo de hoy ${ }^{1}$. Por ello en dicho siglo se empiezan a desarrollar estudios y teorías más estructuradas sobre el ingreso y los riesgos que corren los empresarios. Se privilegian las obras de Alfred Marshall, Max Weber Ronal Coase, James Burham, Joseph Alois Schumpeter, Frank H, Knight. De la escuela keynesiana, el propio Keynes y Joan Violet Robinson. Escritores contemporáneos Arthur H. Cole, John Kenneth Galbraith, Wright Mills, Thorstein Bunde Veblen, Werner Sombart y Douglas North. Los teóricos y sus obras se enlistan en la Tabla I.

\section{Aportes de los Neoclásicos.}

Los economistas neoclásicos surgieron en la segunda mitad del siglo XIX y se les llama también teóricos de la "utilidad marginal». Derivaron sus concepciones teóricas del enunciado de utilidad expresado por los clásicos, llegando a elaborar una teoría subjetiva del valor que es la base de dicha corriente. El iniciador de la corriente neoclásica fue Herman Heirinch Goseen que estudió las leyes de la conducta humana, basado en el utilitarismo y el consumo individual, con un soporte matemático. Los teóricos neoclásicos reconocidos surgieron casi al mismo tiempo y fundaron las principales escuelas de la utilidad marginal: la austriaca o psicológica (Carl Menger, F. Von Weiser y Eugen Von Bohm-Bawerk), la escuela inglesa o de Cambridge (W. Stanley Jevons y Alfred Marshall) y la escuela matemática o de Lausana ( León Walras y Wilfredo Pareto).

Alfred Marshall, introdujo en sus enseñanzas las críticas a la Escuela Clásica inglesa (principalmente, Smith, Ricardo, Malthus y Stuart Mill) procedentes del historicismo alemán y del socialismo, así como también de la escuela marginalista. El resultado de sus esfuerzos fue la denominada "síntesis neoclásica» base de la teoría económica moderna. En 1890 escribe su obra capital, Principios de Economía e Industria y Comercio. Cuando se refiere a la empresa, emplea los términos negocio y grandes empresas: «El término negocio se emplea aquí en un sentido amplio para incluir toda provisión de las necesidades de los demás que se lleve a cabo en espera de una compensación directa o indirecta de aquellos que se benefician con ella, en oposición a la satisfacción de las propias necesidades y a aquellos buenos servicios que se prestan por amistad y afecto familiar ${ }^{2}$. Y conforme se iba desarrollando la industria se dio paso a las grandes empresas: «Así la atención general se fijó, a la larga, en el gran cambio que venía produciéndose

TABLA I. PRINCIPALES TEÓRICOS NEOCLÁSICOS, KEYNESIANOS Y desde hacía tiempo en la organización CONTEMPORÁNEOS.

\begin{tabular}{|c|c|c|c|}
\hline No. & Teórico & Obra & Año \\
\hline 1 & Alfred Marshall & Principios de economía e industria y comercio. & 1890 \\
\hline 2 & Max Weber & La ética protestante y el espíritu del capitalismo. & 1904 \\
\hline 3 & John Maynard Keynes & Teoría general de la ocupación, el interés y el dinero. & 1936 \\
\hline 4 & Joan Violet Robinson & La economía de la competencia imperfecta. & 1946 \\
\hline 5 & Ronald Coase & La naturaleza de la empresa. & 1937 \\
\hline 6 & James Burham & La revolución de los directores. & 1941 \\
\hline 7 & $\begin{array}{l}\text { Joseph Alois } \\
\text { Schumpeter }\end{array}$ & $\begin{array}{l}\text { Teoría del desenvolvimiento económico,. } \\
\text { Capitalismo, socialismo y democracia. }\end{array}$ & $\begin{array}{l}1911 \\
1942\end{array}$ \\
\hline 8 & Frank H. Knight & Riesgo, incertidumbre y beneficio. & 1947 \\
\hline 9 & Jonh Kenneth Galbraith & El nuevo estado industrial & 1952 \\
\hline 10 & Wright Mills & La élite en el poder. & 1963 \\
\hline 11 & $\begin{array}{l}\text { Thorstein Bunde } \\
\text { Veblen }\end{array}$ & Teoría de la empresa de negocio. & 1965 \\
\hline 12 & Werner Sombart & $\begin{array}{l}\text { El burgés. } \\
\text { El apogeo del capitalismo. }\end{array}$ & $\begin{array}{l}1982 \\
1984\end{array}$ \\
\hline
\end{tabular}
de la industria, y se vio que el sistema de los negocios pequeños regidos por los propios trabajadores iba siendo sustituido por el de las grandes empresas dirigidas por la habilidad especializada de empresarios capitalistas ${ }^{2}$.

Alfred Marshall, en su obra, había subdividido el papel del empresario en tres funciones principales: la administración, la innovación y la toma de riesgos. Marshall señala: «En la mayor parte de los negocios del mundo moderno, la tarea de dirigir la producción de modo que un esfuerzo dado pueda ser más eficaz para la satisfacción de las necesidades humanas tiene que ser encomendada a un cuerpo especializado de patronos, o para utilizar un término más general, de hombres de

Fuente: Elaboración propia. 
negocios, que se hacen cargo de asumir o correr sus riesgos, reúnen el capital y la mano de obra necesarios para el trabajo, llevan a cabo o ingenian su plan general y vigilan sus menores detalles. Considerando a los hombres de negocios desde un punto de vista, podemos estimarlos como un grado industrial elevado, y desde otro, como intermediarios entre el trabajador manual y el consumidor» ${ }^{2}$.

Todos los autores neoclásicos abordaron, desde una perspectiva individual, el papel del empresario, su función dentro del proceso productivo y la obtención del beneficio, sin llegar a un acuerdo fundamental sobre estos aspectos tan importantes de la teoría empresarial. En todo caso, los aportes de los economistas neoclásicos acerca de la actividad empresarial y del empresario son analizados desde el punto de vista funcional, es decir, le atribuyen al empresario un papel esencial en el proceso productivo y explican sus beneficios por el exitoso cumplimiento de dichas funciones, a pesar de las diferencias que existen en ellas. Max Weber en su obra La ética protestante y el espíritu del capitalismo, señala que: el actual sistema económico capitalista es como un cosmos excepcional en el cual el hombre nace y al que, al menos como tal, le es dado a guisa de edificio imposible de reformar, en donde habrá de vivir, imponiéndole las medidas de su conducta económica, en razón que se encuentra envuelto en la componenda de la economía. Cuando el empresario actúa de continuo en contra de estas medidas, se ve excluido, infaliblemente, de la contienda económica, al igual que el trabajador que no se percata o no le es posible avenirse a ellas, terminando por verse lanzado a la calle, obligado a ingresar, como otros tantos, en las compactas filas de los sin trabajo. Por ende: «El amo absoluto en la vida de la economía, esto es, del actual capitalismo, educa y obliga, valiéndose de la selección económica, los individuos, tanto empresariales como trabajadores, que requiere». ${ }^{3}$ Por ende el empresario neoclásico puede asociarse con el burgués ordenado y racional.

\section{Aportes de los Keynesianos.}

John Maynard Keynes en su obra Teoría general de la ocupación, el interés y el dinero escrito en 1936, aporta su punto de vista sobre el empresario cuando escribe sobre el estado de las expectativas a largo plazo, señala: "Aun haciendo a un lado la inestabilidad debida a la especulación, hay otra inestabilidad que resulta de las características de la naturaleza humana: que gran parte de nuestras actividades positivas dependen más del optimismo espontáneo que de una expectativa matemática, ya sea moral, hedonista o económica. Quizá la mayor parte de nuestras decisiones de hacer algo positivo, cuyas consecuencias completas se desarrollarán a lo largo de una sucesión de años, puede que sean el resultado exclusivo de nuestros instintos de una especie de resorte que nos invita a la acción más que a la inacción, y que no es el resultado de un cálculo, por elemental que sea, de los beneficios esperados y de sus respectivas probabilidades.

El espíritu animal actúa impulsado sólo por sus propias prospecciones, por muy ingenuas que puedan ser y se basa en una serie de cálculos que no serán mucho más exactos que los que se hacen al planear una expedición al Polo sur. Por esto, si nuestros instintos se tornan débiles y el optimismo espontáneo vacila, dejándonos a solas con nuestros cálculos matemáticos de expectativas, el espíritu animal desvanece y muere, aunque los temores a incurrir en pérdidas pueden no tener una base más racional que las esperanzas de obtener beneficios:

"Se puede afirmar, sin miedo, que el espíritu animal depende de las esperanzas puestas en el futuro beneficia a la comunidad, pero la iniciativa individual sólo será adecuada cuando el cálculo y la racionalidad se le añada el apoyo de los instintos, de forma que la idea de contabilizar pérdidas que puede detener a los pioneros se deja a un lado, al igual que el hombre lleno de salud hace caso omiso de la idea de que alguna vez tendrá que morir ${ }^{4}$.

Joan Violet Robinson en su obra «La Economía de la Competencia Imperfecta», define: «El empresario a que nos refiramos en lo sucesivo aparecerá personificado en un individuo. Hemos de hacer notar, sin embargo, que en una compañía anónima ningún individuo aislado es responsable de la dirección última de la empresa, puesto que la responsabilidad descansa nominalmente sobre los accionistas, aun cuando el verdadero control quede enteramente en manos de los directores. Además, la «remuneración del empresario» quizás no sea percibida por los individuos que realmente ejercen las funciones de tal, ya que la actuación de la entidad puede ser dictada por sus directores más influyentes, siendo así que las pérdidas o beneficios resultantes habrán de ser soportados por los accionistas. Pero como queda dicho, nosotros prescindiremos de estas complicaciones y consideraciones al empresario como una unidad indivisible de dirección y de interés ${ }^{5}$.

Robinson plantea por una parte, de acuerdo a las capacidades personales de los empresarios, dos tipos de empresarios, el empresario marginal y el especializado: «En algunas industrias que no exigen especiales dotes pueden ser marginales aquellos empresarios que tienen la mayor habilidad genérica, pues son aquellos que podrán encontrar más fácilmente otro empleo distinto. En otras industrias en las que una gran capacidad específica tenga una posibilidad de obtener altas remuneraciones, los mejores empresarios serán los últimos en desplazarse a otras actividades en las que su talento les proporcione una mayor ventaja sobre los demás, y los empresarios marginales serán los menos competentes, pues serán ellos los que ante un descenso de los beneficios sean los primeramente impulsados a desplazarse hacia otra industria». ${ }^{5}$ Por otra parte, al 
comparar el monopolio con la competencia imperfecta, señala que «la reorganización de las industrias puede introducir la especialización de las empresas por el proceso de desintegración horizontal y vertical y puede haber un aumento muy grande en el rendimiento».... «Si cabe obtener economías técnicas a base del aumento de magnitud de las empresas, el monopolista reorganizará las industrias en unidades menos numerosas y más eficaces y la productividad media física de los factores aumentará». ${ }^{5}$

Puesto que «desde el punto de vista de toda la industria para la cual el empresario es un factor de la producción exactamente equiparable a los demás...» ${ }^{5}$ «El monopolista tenderá a aumentar la magnitud de las unidades productivas, con el fin de reducir los costes repartiendo la remuneración del empresario (que queda a las órdenes del monopolista como gerente) sobre una producción mayor; sin embargo, como se ha supuesto que la oferta de los empresarios era perfectamente inelástica para la industria, el intento del monopolista de aumentar el tamaño de las empresas y despedir a algunos empresarios daría por resultado una disminución de la retribución de los empresarios, lo cual reduciría la magnitud óptima de las empresas. Y si todos los empresarios fuesen empleados por el monopolista, su remuneración se reduciría hasta el punto en que la nueva magnitud óptima de las empresas quedaría inalterada. Pero si caben economías técnicas mediante una expansión de las empresas, el monopolista empleará el total de empresarios, aun cuando la remuneración de éstos empresarios quedarán permanentemente parados o se verán obligados a buscar otra ocupación, tal como el trabajo no cualificado». ${ }^{5}$

\section{Aportaciones de los teóricos contemporáneos.}

A finales del siglo XIX y principios del XX los economistas: J.S. Mill, Francis A. Walter, Alfred Marshall, J.B. Clark y Thorstein Veblen y otros, integraron un pequeño grupo de intelectuales que mostraban un especial interés en el empresario. Un destacado economista del siglo XX es Joseph Schumpeter, sus numerosas contribuciones a la teoría de la empresa sirven como punto de partida para discusiones contemporáneas, facilitó el consenso general alcanzado por la mayoría de los economistas respecto a los dos indispensables aspectos del empresario: innovar y tomar riesgos. ${ }^{6}$ Popularizó el concepto de destrucción creativa como forma de describir el proceso de transformación que acompaña a las innovaciones. El principal aporte de Schumpeter es la concepción cíclica e irregular del crecimiento económico, desarrollada en 1911 en su Teoría del desenvolvimiento económico. En ella recoge su teoría del "espíritu emprendedor» (entrepreneurship), derivada de los empresarios, que crean innovaciones técnicas y financieras en un medio competitivo en el que deben asumir continuos riesgos y beneficios que no siempre se mantienen. Todos estos elementos intervienen en el crecimiento económico irregular.
Históricamente, el período de mayor gloria de los empresarios comprende dos momentos en la historia económica de Occidente, uno que es el siglo XIX en Inglaterra, cuando tienen lugar la primera y la segunda Revolución Industrial, y otro en Estados Unidos en el periodo que transcurre entre el término de la Guerra de Secesión y la Primera Guerra Mundial. Nunca antes ni nunca después el espíritu de empresa se encarnaría tan marcadamente en individualidades que descollaban por la fuerza de su carácter y la creatividad para hacer surgir enormes corporaciones, gigantescas fortunas y nuevos procesos productivos. La observación de estas realidades llevó a Schumpeter a formular su teoría del «empresario emprendedor», donde lo definió como un modelo humano en el que reconocía como el gran agente del portentoso desarrollo económico que trajo la época moderna. Esa idea del empresario, ha marcado más que ninguna otra la cultura - y la mitología, habría que decir- de los hombres de negocios. ${ }^{7}$

De acuerdo con Schumpeter, este empresario innovador, creativo e incluso subversivo y revolucionario es el principal responsable del desarrollo económico. En consecuencia, no todos los empresarios merecen el título de entrepreneur. En este sentido, es demasiado amplia la definición clásica de Jean Baptiste Say de que «la función empresarial consiste en unir y combinar a los diversos factores de la producción», porque se le escapa la dimensión dinámica que para Schumpeter es el rasgo esencial de la actividad empresarial. La idea de Say de desarrollo económico sigue conectada a la noción de «corriente circular de la vida económica» y por esto no reconoce el ingrediente adicional y necesario que es la ganancia, la cual resulta de las innovaciones que interrumpen la «corriente» y rompen las rutinas establecidas en cualquier campo de la producción industrial.

Schumpeter en aras de definir la función del empresario señala que «es un prejuicio suponer que el conocimiento del origen histórico de una institución o tipo, nos muestra inmediatamente su naturaleza sociológica o económica. Tal conocimiento nos conduce a veces a su comprensión, pero no proporciona directamente una teoría sobre ella....porque la especialización creciente puede autorizar a destacar las funciones o cualidades que sean más difíciles de reconocer bajo condiciones más primitivas, por hallarse mezcladas con otras....En la posición general del jefe de una horda primitiva, es difícil separar el elemento de empresario, de los otros elementos. $\mathrm{Y}$ por eso los economistas antiguos, hasta el más joven de los Mill, no lograron separar al capitalista del empresario, pues el industrial de hace cien años, era indudablemente ambas cosas ${ }^{8}$.

En ese sentido: «El empresario de tiempos antiguos no sólo era por lo general capitalista, sino que también era su propio experto técnico -lo mismo que lo es aún hoy día en el caso de las empresas poco importantes-, en la 
medida en que no se necesitara un especialista profesional para casos especiales. Era también (y es) en muchas ocasiones su propio abogado. Y su trabajo se componía regularmente de varias de tales funciones. Llevar a cabo combinaciones nuevas no es más una vocación, que la realización y ejecución de decisiones estratégicas, a pesar de ser precisamente esta función, y no el trabajo rutinario, lo que caracteriza al jefe militar. Por lo tanto, la función especial del empresario debe aparecer mezclada con otras clases de actividad que por regla general serán más conspicuas que la esencial»8. Con ello Schumpeter se refiere básicamente a la innovación y al papel que ella representa en el desarrollo del sistema económico.

Sí se tiene por un lado una función característica y por otro una ganancia característica precedente del ejercicio de esta función, se puede comenzar una tarea de conceptualización:

1. En primer lugar se necesita una palabra. Schumpeter sugiere que la palabra empresario sea utilizada, pero está bastante claro, desde luego, que puesto que esta función empresarial no es neologismo, llevará consigo otros significados. En consecuencia, no debería tener objeción a expresiones tales como dirigente de negocios o simplemente innovador o similares. Lo esencial es el reconocimiento del agente característico que observamos y no la palabra.*

2. En segundo lugar, al aplicar su concepto a la realidad encuentra que la vida nunca presenta esta función por y en sí sola. En el caso del empresario es incluso difícil imaginar el que un hombre no haga nada sino montar nuevas combinaciones y que haga esto toda su vida. En particular, un industrial que crea una empresa internamente nueva se quedará con una actividad meramente administrativa a la que se confinará más y más a medida que se haga más viejo.

3. En tercer lugar, puesto que el empresario, como se ha definido, consiste esencialmente en hacer cosas que no se hacen generalmente en el curso ordinario de la rutina de negocios, es esencialmente un fenómeno que cae dentro del aspecto más amplio del liderazgo. El liderazgo puede consistir, como en las artes, simplemente en hacer algo nuevo; por ejemplo, en crear una nueva forma de auto expresión pictórica, pero en otros casos, influenciar a otras personas con métodos distintos del ejemplo es más importante. El caso del fenómeno que llamamos la facultad de ser obedecido. Aquí no es tanto el ejemplo como la acción directa sobre otras personas lo que importa. La naturaleza y función del liderazgo empresarial, sus causas y efectos, constituyen por tanto, un muy importante tema de investigación.

4.En cuarto lugar, la característica retribución al empresariado, presenta dificultades por sí misma.
Es ciertamente una retribución a la actividad personal. En este sentido, podemos estar tentados a llamarlo una forma de salario, como en realidad han hecho en el pasado muchos economistas. Por otro lado, está claro que si la gente reaccionara de igual manera y simultáneamente a la presencia de nuevas posibilidades no habría beneficio empresarial alguno: si todo el mundo hubiera estado en condiciones para desarrollar el condensador de Watt, los precios de los productos que iban a ser producidos con la nueva máquina de vapor se hubieran ajustado inmediatamente, y no hubiera habido ningún excedente sobre los costes para la firma Boulton y Watt.

Finalmente, señala que la función empresarial no tiene que estar incluida en una persona física y en especial una sola persona física. Cualquier medio social tiene su propia forma de cumplir la función empresarial....En alguna ocasión la función empresarial puede y a menudo se ha realizado cooperativamente. Con el desarrollo de las sociedades a gran escala, esto se ha convertido evidentemente en algo muy importante: pueden así ser construidas en una personalidad corporativa-aptitudes que ningún individuo por sí mismo combina-; por otro lado, las personas físicas constituyentes inevitablemente deberán interferir entre sí hasta cierto punto, y muy a menudo en gran manera. Las personas dirigentes, en especial aquéllas que llevan el título de Presidente o Presidente del Consejo, pueden ser meros coordinadores o incluso figurones... ${ }^{9}$

Para Schumpeter «el empresario no es nunca quien soporta los riesgos...quien concede el crédito sufre las pérdidas si fracasa la empresa. Pues si bien responde cualquier propiedad de que disponga el empresario de las resultantes de la operación, no es esencial tal posición de riqueza, aunque sea ventajosa. Aun en el caso de que el empresario se financie con ganancias anteriores, o de que aporte los medios de producción pertenecientes a su negocio «estático», el riesgo recae sobre él como capitalista o como propietario de tales bienes, pero no como empresario. El riesgo no es en ningún caso un elemento de la función del empresario. Y si bien es cierto que corre el riesgo de perder su reputación, la responsabilidad económica directa del fracaso no recae sobre él.....Como hemos vista, el promotor puede ser el tipo acabado del empresario, que en este caso se limita estrictamente a su función característica: la puesta en práctica de nuevas combinaciones ${ }^{9}$.

A mediados del siglo XX, Joseph A. Schumpeter comienza a hablar del ocaso de la función del empresario, explicando que dicha función consistía en «reformar o revolucionar el sistema de producción, explotando un invento, o, de una manera más general, una posibilidad técnica no experimentada para producir una mercancía nueva o una mercancía antigua por un método nuevo, para abrir una nueva fuente de provisión de materias primas o una nueva salida para los productos, o para reorganizar una nueva 
empresa». Para Schumpeter esta función de lograr ciertos objetivos solo la podía desarrollar una pequeña fracción de la población con determinadas características a los cuales se les denominaba empresarios ${ }^{10}$.

Schumpeter sostiene que con la misma evolución capitalista, la unidad industrial gigante, perfectamente burocratizada y automatizada, no solamente desalojaría a la empresa pequeña y de volumen medio, expropiando a sus propietarios, sino que terminaría por desalojar al empresario y por expropiar a la burguesía como clase, perdiendo con ello no sólo su renta sino también, lo que es más importante, su función. Schumpeter está observando el inicio de un proceso en el cual se sustituyen al empresario individual y su empresa, por los consejos administrativos de las grandes empresas monopólicas, con lo cual, se está afectando de forma directa las instituciones, los valores y las ideas sobre las que descansa el régimen capitalista de producción. Debilita el poder del propietario sobre sus bienes, convirtiéndolo en un simple poseedor de acciones de la gran empresa, perdiendo el control de la misma y eliminando la libertad individual para decidir lo que ha de hacer con su capital y con su empresa ${ }^{10}$.

Ronald Coase publica en 1937 un artículo que será muy influyente para la teoría económica al explicar la naturaleza de la empresa ${ }^{11}$. Coase sostiene que fuera de la empresa, los movimientos de los precios dirigen la producción, que se coordina mediante una serie de transacciones de intercambio en el mercado, pero que dentro de la empresa, estas transacciones de los mercados se eliminan y en lugar de la complicada estructura del mercado con transacciones de intercambio surge el empresario-coordinador que dirige la producción.

Para Coase el empresario y la empresa sustituyen el mecanismo de los precios, esto se debe a que el empresario logra realizar una serie de actividades y transacciones dentro de su empresa por debajo del costo que esas mismas transacciones le significarían si el empresario las consiguiera a través del mecanismo de los precios del mercado. Por ello para Coase, la principal razón de la conveniencia del establecimiento de una empresa es que hay un costo en el mecanismo de los precios. Lo que descubre Coase es que las transacciones realizadas en el mercado tienen un costo debido a que los actores económicos tienen un conocimiento incompleto del sistema de precios de los mercados y esto genera riesgos e incertidumbres; pero al momento de que el empresario asume la coordinación de una actividad productiva entre distintos factores, está asumiendo la responsabilidad de los costos del riesgo y la incertidumbre al tratar de pronosticar las necesidades y gustos de los consumidores ${ }^{12}$.

James Burnham en su obra The Managerial Revolution (La revolución Gerencial), publicado en 1941, alertó a los norteamericanos sobre el creciente peligro de lo que él llamaba «la revolución gerencial». Burnham afirmaba que el activo papel de los gerentes había llevado a una situación en la cual: «el control de los grandes capitalistas, el control basado en los derechos de propiedad privada sobre los medios de producción y en el ejercicio de aquéllos es, aunque todavía real, cada vez más tenue, indirecto 0 intermitente ${ }^{13}$.

En plena Segunda Guerra Mundial, Burnham consideraba que se estaban viviendo tiempos de cambio, tiempos que implicaban una revolución social de proporciones mundiales y que conducirían a la aparición de una nueva sociedad. Esta revolución implicaría cambios drásticos en todas las instituciones (relaciones de propiedad, modos de producción, regímenes y organizaciones políticas, estructura legal de la sociedad); significaría también cambios en las instituciones culturales y la cosmovisión humana del mundo. Pero el elemento más trascendental de esta revolución para Burnham es el ascenso de una nueva elite política y económica a lo largo del mundo: los hombres que controlaban el poder y los privilegios en la sociedad capitalista (la burguesía) serían sustituidos por otros individuos más aptos para enfrentar los nuevos tiempos (los gerentes, los managers).

Plantea Burnham el paso de una sociedad capitalista a una sociedad gerencial: este proceso se inició en 1914 y culminaría 80 o 90, años después. Esta revolución comparable con la transición del feudalismo al capitalismo, consolidaría a los gerentes como la clase gobernante dentro de la sociedad. La dominación gerencial estaría garantizada como el principal poseedor de los medios de producción aunada a la práctica desaparición de la propiedad individual.

El ascenso de la clase gerencial se daría a raíz de que controlan y administran el proceso productivo y los medios de producción propiedad del Estado y con el paso del tiempo, llegarían a controlar al mismo Estado. Los primeros indicios de este proceso lo localiza Burham en el New Deal, donde un grupo de administradores gubernamentales se encargaron de reactivar a la economía norteamericana. Otro elemento que soporta esta teoría es el fortalecimiento de los Consejos de Administración de las Corporations como señalaba Burnham, la separación entre la posesión y el control de los activos. Los fenómenos que fortalecerían este proceso serían:

- La burguesía, los capitalistas, no administran ya sus empresas sino que delegan la responsabilidad a los gerentes y cada vez pierden más facultades administrativas sobre sus bienes; este proceso concluiría con la eliminación del control de los capitalistas sobre sus bienes.

Que el estado, entidad abstracta, asuma el control sobre los medios de producción y el proceso productivo delegando las labores relativas a su organización a 
los gerentes, a los individuos entrenados para organizar, coordinar y dirigir la producción.

- La cada vez más compleja organización de la producción que requiere a sus propios especialistas.

Este movimiento afectaría a todas las naciones modernas.

Frank H. Knight en su obra Riesgo, Incertidumbre y Beneficio recupera la figura del empresario, estableciendo la diferencia entre riesgo e incertidumbre, Knigth señaló en 1921 que el riesgo es simplemente una parte del costo total de la empresa, que puede cubrirse por medio de un seguro, mientras que la función de la incertidumbre no es asegurable, por el contrario, es la función propia del empresario y la razón de su beneficio, al estar vinculada con su habilidad para especular o prever las situaciones futuras del mercado. ${ }^{14}$

Señala que: «bajo el sistema de empresa, una clase social especial, los hombres de negocios, dirigen la actividad económica; son, en un sentido estricto, los productores, mientras que la gran masa de la población les suministra simplemente servicios productivos, poniendo sus personas y propiedades a disposición de esta clase; los empresarios también garantizan a los que prestan servicios productivos una remuneración fija. El definir con exactitud estas funciones y describirlas en toda la estructura social será una larga tarea, pues la especialización nunca es completa; pero al final encontraremos que, en una sociedad libre, las dos son esencialmente inseparables. Cualquier grado del ejercicio del juicio o de la realización de las decisiones está, en una sociedad libre, acompañado de un correspondiente grado de asumir incertidumbre, de tomar la responsabilidad de aquellas decisiones ${ }^{15}$.

Por otra parte, establece los principios que determinan el beneficio del empresario con más precisión y en forma de leyes de la oferta y la demanda. Al respecto señala que «la demanda de empresario, como la de cualquier agente productivo, depende también directamente de la oferta de los demás agentes» En el caso de la oferta argumenta: «la oferta de empresarios implica los siguientes factores: a) capacidad, con los varios elementos incluidos en ella; b) buena voluntad; c) facultad de dar suficientes garantías y d) la coincidencia de estos factores. Si la sociedad en su conjunto asegura una alta calidad de dirección para sus empresas será mediante una coincidencia de la capacidad con la buena voluntad o de los tres factores, así como también mediante una abundante oferta de los elementos por separado.

La buena voluntad, más la facultad de dar garantías, no acompañados por la capacidad, conducirán, evidentemente, a una disipación de recursos, mientras que la capacidad sin los otros dos factores será simplemente ineficaz. Encontrar hombres capaces de dirigir negocios eficazmente y asegurarles las posiciones de responsabilidad es quizá el único problema de máxima importancia de la organización económica en lo referente a la eficiencia». Establece una relación directa de la oferta de cualidades de empresario en la sociedad y el número y volumen de sus unidades productivas, al señalar que dicha oferta es uno de los principales factores que lo determinan: «Es una opinión corriente y quizá justificable que la mayoría de los otros factores tienden hacia una mayor economía con una creciente dimensión del establecimiento, y que la principal limitación de la dimensión es la capacidad en la dirección. Si esto es cierto, la capacidad para organizar grandes empresas con éxito, cuando tiene efecto, debe tender a asegurar recompensas muy grandes».

En relación a la renta del empresario particular, enfatiza que tenderá en general a ser más grande, si: “ $1^{\circ}$, según sea su propia capacidad y buena suerte; y $2^{\circ}$, y quizá más importante, según exista en la sociedad una escasez de la propia confianza combinada con la facultad de dar efectivas garantías a los empleados. La abundancia o escasez de la simple capacidad para dirigir los negocios con éxito influye relativamente poco en el beneficio; el hecho principal es la precipitación o timidez de los empresarios (real y potencial) como clase, al hacer ofertas de precios de servicios productivos. El beneficio del empresario, al ser residual, está determinado por la demanda de estos otros servicios, cuya demanda es una cuestión de la confianza de los empresarios en sí mismo como clase, más bien que sobre una demanda de servicio de empresario en un sentido directo ${ }^{15}$.

John Kenneth Galbraith en su obra El nuevo estado industrial señala que la teoría económica clásica no dedicó gran interés al empresario por entender que no era un concepto operativo y afirma: «En la tradición económica clásica- la de Adam Smith, David Ricardo, Thomas Malthus, John Stuart Mill y Alfred Marshall - a medida que los conceptos se definían más precisamente se suponía que la empresa comercial o industrial era pequeña en relación con la magnitud del mercado al que concurrían. El precio percibido por la empresa era impersonal y estaba competitivamente determinado por el mercado. Lo mismo ocurría con los precios pagados a sus suministradores. También los salarios quedaban fijados por el mercado; y el interés de los capitales tomados en préstamo; los beneficios mismos se reconducían a un nivel competitivo, y se suponía estable la tecnología por lo cual el volumen ideal de la producción para la empresa quedaba externamente fijado por la relación de los costes al precio del mercado en los varios niveles del producto. En tal situación, el director o dueño de la empresa no tenía poder alguno para influir en los precios, los costes, los salarios, el interés, el nivel de producción o en los beneficios, ya que todo estaba regulado por los mecanismos de libre competencia del mercado. Por ello, la función del empresario dentro de este marco teórico carecía de importancia» ${ }^{16}$. 
Por ende, para Galbraith el verdadero empresario, es decir, aquel que ha arriesgado su propio capital en la construcción de la empresa está siendo desplazado por un nuevo grupo de profesionales: "Al formarse la compañía moderna y construirse la organización requerida por la tecnología y la planificación modernas, con la separación del propietario del capital y el control de la empresa, el empresario ha dejado de existir como persona individual; en la empresa industrial madura...el empresario, como fuerza directora de la empresa queda sustituido por la gerencia, el management ${ }^{16}$.

John K. Galbraith sostiene que los empresarios individuales que unían la propiedad o el control del capital con la capacidad de organizar los demás factores de la producción, y en la mayoría de los casos, con la capacidad de innovar fueron sustituidos en la jefatura de las empresas mercantiles al formarse la gran sociedad anónima moderna y al constituirse la organización requerida por la tecnología y la planificación modernas.

Se considera al empresario como un personaje perteneciente a cierta etapa de la industrialización y que está condenado a desaparecer, conforme va madurando este proceso. Galbraith describe este proceso: «En efecto: la vida del gran empresario tiene que compararse con la del macho de la especie Apis mellifera. Este animal realiza su acto fecundador y paga por él con la muerte. Los viejos empresarios combinaron firmas que eran todavía tecnológicamente complejas...Pero el acto de la concentración o combinación añadió a la empresa nuevas instalaciones productivas, nuevos productos y por tanto, la necesidad de especializarse por la función y por el conocimiento. Antes o después se presentarían tareas más complejas de planificación y de control. Luego, la tecnología, por su propia dinámica, presentó sus exigencias de capital y de talento especializado, con la necesidad adicional de una planificación cada vez más amplia y detallada. De este modo, la creación del empresario se salía inexorablemente del alcance de su autoridad. El empresario podía crear, construir y ejercer su influencia durante algún tiempo. Pero su creación, si es que había de servir a los fines para los cuales se había creado, exigía la sustitución del mismo creador. Sólo un grupo de hombres con información especializada podía dirigir lo que había creado el empresario „ ${ }^{16}$.

El último acto del empresario, como tal, sería retirarse del escenario mediante un acto de auto inmolación, para ser substituido por una multiplicidad de dueños, delegando su poder a una administración múltiple, mejor equipada para asegurar el crecimiento de la compañía. El empresario como fuerza directora de la empresa fue sustituido no solo por la dirección, el management o consejo directivo, sino por una numerosa burocracia empresarial. El consejo directivo para Galbraith es una entidad colectiva imperfectamente determinada, que está constituida por el presidente de la sociedad y de la junta, los vicepresidente que responden de un equipo importante o de un departamento, los que ocupan otras posiciones importantes en los equipos y en algunos casos, los jefes de división y de departamento.

El grupo incluye por tanto una parte muy reducida de las personas que participan como informadores en los grupos de decisiones. El grupo general decisorio es, en cambio muy grande, abarca desde los funcionarios más importantes de la sociedad hasta el perímetro más extenso, hasta los empleados y obreros cuya función es atenerse más o menos mecánicamente a la instrucción de la rutina: sólo éstos quedan fuera del grupo, el cual abarca, pues, a todos que aportan conocimiento especializado, talento o experiencia en la elaboración de decisiones de grupo. Este grupo es la inteligencia que guía a la empresa, el cerebro de la empresa, y no el estrecho grupo de management, a esta amplia y numerosa burocracia empresarial John K. Galbraith la denomina tecnoestructura.

Charles Wright Mills se enfocó en las responsabilidades de los intelectuales de la sociedad posterior a la Segunda Guerra Mundial, y aporta relevancia a partir de observaciones académicas desinteresadas como en «El Aparato Público Inteligente» donde desafío las políticas de las élites institucionales de los «Tres»: Economía, Política y Militar. Para Mills «las carreras económicas de los muy ricos no son ni de hombres de empresa ni burocráticas. Además, entre ellos, muchos de los que dirigen las empresas de sus familias son exactamente tan hombres de empresa o tan burócratas como los que no han gozado de una herencia semejante. «Empresario y burócrata" son expresiones de la clase media y con connotaciones mesocráticas, y no pueden extenderse hasta abarcar las coyunturas para hacer carrera de la alta vida económica en los Estados Unidos.

La engañosa expresión empresario, no tiene el mismo sentido cuando se aplica a pequeños hombres de negocios que cuando se aplica a los individuos que han llegado a poseer las grandes fortunas norteamericanas. La modesta fundación burguesa de un negocio, y la ampliación gradual de ese negocio hasta convertirse en una gran compañía anónima norteamericana, no es la representación adecuada de los fundadores de fortunas en los niveles más elevados. El empresario, de acuerdo con su imagen clásica, es el que se da por supuesto que ha corrido un riesgo, no sólo respecto de su dinero sino también respecto de su misma carrera: pero una vez que el fundador de un negocio ha dado el gran salto, por lo general, no vuelve a correr riesgos grandes, ya que empieza a gozar de la acumulación de ventajas que le llevan a la gran fortuna. Si hay algún riesgo, habitualmente es otro quien lo corre". ${ }^{17}$

La sociedad por acciones en la empresa moderna fracciona el poder de los propietarios y no les permite un control directo sobre cada compañía. La dirección del proceso productivo, el control del personal y la distribución 
del producto pasan entonces a manos de quienes ocupan las posiciones ejecutivas de la empresa. Se trata, por regla general, de altos funcionarios con un elevado grado de responsabilidad hacia la empresa que los ha formado y que en ocasiones, incluso los ha hecho partícipes de un minoritario paquete de acciones que al tiempo que legaliza su entrada formal a la clase, acrecienta su lealtad hacia los objetivos de la empresa y hacia los principios capitalistas en general. A los dueños del capital se suma ese grupo de «coordinadores profesionales» a quienes C. Wright Mills ${ }^{17}$, concede el poder decisorio pero muy poca iniciativa y de quienes Galbraith piensa que han ocupado el lugar de una especie en extinción.

Thorstein Bunde Veblen fue fundador, junto con John R. Commons, de la corriente institucionalista en las ciencias sociales. Su fama se debe a libro La teoría de la clase ociosa (1899) en los que critica de forma apasionada la evolución de la sociedad y la economía de su país. La teoría de la clase ociosa y La teoría de la empresa económica son una construcción alternativa a las teorías marginalistas del consumo y la producción. Uno de los grandes méritos del análisis de Veblen del capitalismo consiste en haber prestado atención especial a la función real del empresario: «El hombre de negocios, especialmente aquel de amplia y reconocida discreción, se ha convertido en una fuerza determinante en la industria, debido a que, a través del mecanismo de inversiones y mercado, controla las plantas y procesos que, a su vez marcan el rumbo a los demás elementos de la industria y determinan la dirección de su movimiento....De ahí que el interés permanente de la humanidad civilizada gire en torno de él y de su destino» ${ }^{18}$.

Veblen va más allá al trazar una distinción entre el «capitán de la industria y el «capitán de la empresa». El capitán de la industria, al cual ve personificado en el ingeniero, tiene un interés racional en el crecimiento. Por lo tanto, está intrínsecamente orientado hacia la comunidad y no tiende a restringir de manera artificial la producción y el comercio. Veblen señala que «como proposición comercial, al gran hombre de negocios le es indiferente que los trastornos que sus transacciones producen en el sistema industrial ayuden o estorben al sistema en general, excepto en la medida en que persiga ulteriores fines estratégicos. Pero la mayoría de los modernos capitanes de industria, y particularmente los más importantes, persiguen tales fines ulteriores. En verdad, es este trabajo de estrategia comercial de largo alcance lo que ha dado pleno derecho al título de «capitanes de industria». Esta vasta estrategia comercial constituye el rasgo más admirable de los grandes hombres de negocios que manejan la suerte de la humanidad civilizada con fuerza y perspicacia» ${ }^{18}$.

Otra característica del capitán de industria que señala Veblen es la reducción de tareas comerciales: «Al eliminar transacciones comerciales innecesarias y maniobras industrialmente inútiles por parte de firmas independientes, el promotor de combinaciones logra su éxito más notable. De manera que casi no es una exageración afirmar que probablemente el mayor y sin duda el más seguro e incuestionable servicio prestado por los grandes capitanes de industria modernos es esta reducción de las negociaciones que deben realizarse, este absoluto retiro de los hombres de negocios y la anulación definitiva de posibilidades para la empresa privada...El papel heroico del capitán de industria es, precisamente, el de liberador del exceso de administración comercial. Es la eliminación que el más importante hombre de negocios hace de los demás hombres de negocios ${ }^{18}$.

El capitán de la empresa, en cambio, es esencialmente un especulador que intenta "obtener algo a cambio de nada». En sentido histórico corresponde al surgimiento del capitalismo puramente financiero o, según la tradición marxista, a la última etapa del capitalismo», tal como la plantean Lenin y Rodolf Hilferding. Por ello Veblen insiste en que los empresarios dedicados al crecimiento económico racional (sean ingenieros o no) no deben ser confundidos con los especuladores que utilizan la producción para sus propios fines «dinásticos».

De acuerdo con Veblen, el desarrollo industrial moderno opera según una lógica mecanicista que está destinada a rebasar cualquier restricción basada en "derechos naturales». Para Veblen el problema fundamental al que se enfrenta el mundo actual se deriva de la «discrepancia entre empresa e industria», esta discrepancia señala es que en el mundo moderno «las industrias mecanizadas están en una posición dominante y el empresario se ha convertido en una fuerza de control en la industria». Por otra parte, este empresario dominante no es un simple ingeniero, puesto que entiende el proceso productivo y lo controla (generalmente delegando autoridad), pero su control no se basa del todo en su experiencia.

Por lo general, llegar a los niveles más altos de la administración empresarial también requiere vínculos familiares especiales, relaciones bancarias, viejos lazos escolares o alguna otra forma de contacto personal, que se acepta como garantía de lealtad, confianza, alianza ideológica y a final de cuentas, activa complicidad operativa ${ }^{19}$.Veblen señala que: «En la medida en que las transacciones pecuniarias se reducen a rutina, se puede prescindir del capitán de la industria. Este resultado, innecesario es decirlo, pertenece todavía a un futuro indefinido. Las mejoras hechas a favor de los propietarios del dinero en las instituciones modernas tienden, en otro campo, a sustituir a la «desalmada» sociedad anónima por el capitán de industria, y favorecen así la posibilidad de prescindir de la gran función de propiedad que corresponde a la clase ociosa»20.

Werner Sombart en su obra El Burgués señala en un lenguaje metafórico que la vida económica esta compuesta de un cuerpo y de un alma. "Las formas en que se desenvuelve la vida económica - formas de producción, de distribución, organizaciones de todas clases, en cuyo marco el hombre satisface sus necesidades económicasconstituirían el cuerpo económico». A este cuerpo se 
contrapone el espíritu económico, el cual comprende «el conjunto de facultades y actividades psíquicas que intervienen en la vida económica: manifestaciones de la inteligencia, rasgos de carácter, fines y tendencias, juicios de valor y principios que determinan y regulan la conducta del hombre económico».

Sombart nombra espíritu de empresa «al compendio de todas las características psíquicas que son necesarias para la feliz ejecución de una empresa. Estas características varían por un lado, con las muy diversas funciones que han de ser desempeñadas por un empresario, por otro lado se diferencian también en magnitud toda vez que las tareas a llevar a cabo por un empresario son extraordinariamente distintas en extensión según las dimensiones y dificultades de la empresa» ${ }^{21}$.

Por otra parte en su estudio sobre la burguesía, Werner Sombart ${ }^{22}$, asegura que el espíritu de empresa es el verdadero espíritu del capitalismo y que a su vez el espíritu de empresa no está dado por la procedencia del capital sino por el empresario que administra las sumas de dinero. Con ello pone de manifiesto la tendencia del capitalismo moderno a diluir la propiedad del capital en la medida en que se fortalece la gran corporación, pero también la enorme importancia que el propio burgués atribuye a su personalidad de hombre de empresa.

Sombart en su obra El apogeo del capitalismo, señala que «el rasgo especial característico de la época de apogeo del capitalismo es el cambio de toda la dirección en la vida económica, la cual pasa a manos de los empresarios capitalistas, que a partir de este momento -superada la marcha a través de los órganos del Estado-, transformados en los sujetos económicos de la esencia profunda de la economía capitalista, son los únicos organizadores del proceso económico, en tanto que éste se desarrolla dentro de los cuadros del sistema económico capitalista» ${ }^{23}$. Las funciones que Sombart le atribuye al empresario son: unificar al capital y trabajo, determinar la dirección y el volumen de la producción, establecer la relación entre producción y consumo. Designa la forma capitalista de la dirección económica como economía de empresa y considera que el empresario se desenvuelve a su propio riesgo, o sea que sobre él recaen todas las posibilidades de ganancia 0 pérdida.

Alfred D. Chandler, Jr., dio énfasis en que la importancia de organizar y dirigir grandes empresas se amplió en una «revolución administrativa», en su obra La mano visible: la revolución de gestión de negocios en América (1977) plantea que «la empresa moderna reemplazó a los mecanismos de mercado en la coordinación de actividades de la economía y en la designación de sus recursos. En muchos sectores, la mano visible de la dirección sustituyó a lo que Adam Smith denominó la mano invisible de las fuerzas del mercado. El mercado continuó siendo el generador de la demanda de bienes y servicios, pero la empresa asumió las funciones de coordinar el flujo de mercancías a través de los procesos de producción y distribución existentes y de asignar el capital y la mano de obra para la producción y la distribución futuras. A medida que la empresa moderna adquirió las funciones realizadas hasta entonces por el mercado, se convirtió en la institución más poderosa de la economía norteamericana, y sus directivos, en el grupo más influyente de los responsables de la toma de decisiones económicas. Por consiguiente, la aparición de la empresa moderna de Estados Unidos trajo consigo el capitalismo gerencial».

Define por lo tanto a la empresa moderna, como aquella que posee dos características específicas: consta de muchas unidades de operación distintas y la dirige una jerarquía de ejecutivos asalariados...La empresa moderna, al incorporar muchas unidades bajo su control, comenzó a operar en lugares diferentes, llevando a menudo diversos tipos de actividades económicas y comerciando en distintas líneas de bienes y servicios. Así, las actividades de estas unidades y las transacciones entre ellas se internalizaron y fueron los empleados quienes las controlaron y coordinaron en lugar de los mecanismos de mercado» ${ }^{24}$.

\section{Taxonomía de empresario.}

La imprecisión del término empresario se observa al incorporar distintas funciones y orientaciones Las aportaciones de los teóricos nos permiten retomar una taxonomía, como se muestra en la Tabla II.

En la evolución histórica del empresario se aprecian ciertas cualidades o características que deben ser remuneradas:

- Por su habilidad, Turgot.

- Por su talento de ejecución; poseer el arte de la supervisión y de la administración, Say.

- Por su habilidad especializada, Marshall.

- Por su asiduidad y habilidad, Mill.

- Por su ingeniosidad, Bentham.

- Por combinar innovaciones, Veblen.

- Por realizar los cálculos y ganancias, Weber

- Por su elevado grado de responsabilidad, Wright Mills.

No obstante, los avances tecnológicos que permiten producciones en series cada vez mayores, a la vez que una mayor productividad de la mano de obra, ensanchan los mercados, ya que las retribuciones salariales crean un mayor poder de compra y las grandes series reducen los costos. Las consecuencias de este proceso es la necesidad de unas unidades de producción de mayor dimensión y consecuentemente un mayor volumen de capital para financiarla. Ante las dificultades de hacer frente a estas exigencias con un solo patrimonio, surgen las grandes sociedades en las que varios propietarios financian conjuntamente la empresa.

Con ellas aparece una nueva figura de empresario, a la vez que comienzan a disociarse los objetivos del empresario y del capitalista, es decir, que la utilidad que define su actuación económica se plantee en forma diferente. La concepción del empresario cambia como consecuencia de la adaptación de la empresa al cambio social. El capital obtenido es confiado a un empresario profesional -que 
TABLA II. TAXONOMÍA SOBRE EL EMPRESARIO.

\begin{tabular}{|l|l|l|}
\hline \multicolumn{1}{|c|}{ Concepto } & \multicolumn{1}{c|}{ De acuerdo } & \multicolumn{1}{c|}{ En desacuerdo } \\
\hline Asumen riesgos & $\begin{array}{l}\text { Cantillo, Say, Knight, (Mises, Menger, Schackle) } \\
\text { Bentham, Mil, Turgot, Sombart, Robinson. }\end{array}$ & Schiuumpeter, Kirzner \\
\hline Son propietarios del capital & Fisiócratas, Smith, (Turgot, Mises), Bentham, Say, Mill. & Walras, Clark, Schumpeter, Kirzner. \\
\hline Son gente excepcional & Say, Mill, Marshall, (Shackle). & Kirzner \\
\hline Son líderes & Marshall, Schumpeter. & Schumpeter, Walras, Clark \\
\hline $\begin{array}{l}\text { Combinan factores, pero no son } \\
\text { líderes }\end{array}$ & Walras, Clark. & Marshall, Say, Mill \\
\hline Crean equilibrio & Walras, Clark, (Schultz). & Schumpeter \\
\hline Crean desequilibrio & Schumpeter, (Schackle). & Walras, Clark \\
\hline Son innovadores & Schumpeter, (Thunen, Weber). & Say \\
\hline Están más alertas & Cantillon, Clark, Kirzner, (Menger). & Fisiócratas \\
\hline El empresario es un agricultor & Quesnay y Badeau, Say & \\
\hline Director, dirigen & Knight, Galbraith, Sombart,Veblen. & \\
\hline $\begin{array}{l}\text { Fuerza impulsora de la } \\
\text { economia }\end{array}$ & Sombart. & \\
\hline Dirigente de negocios & Schuimpeter. & \\
\hline Coordinador & Coase, Wright, Mills. & \\
\hline $\begin{array}{l}\text { Capitanes de empresa, } \\
\text { capitanes de industria }\end{array}$ & Veblen. & \\
\hline Combinan innovaciones & Veblen, Schumpeter, Marshall. & \\
\hline $\begin{array}{l}\text { Liberador delexceso de } \\
\text { administración comercial }\end{array}$ & Veblen. & \\
\hline Poseen un espíritu animal & Keynes, Robinson. & \\
\hline $\begin{array}{l}\text { Burocracia empresarial que } \\
\text { dirige: la tecnoestructura }\end{array}$ & Galbraith. & \\
\hline Gerencia & Burnham, Marshall. & \\
\hline Combinan factores & $\begin{array}{l}\text { Cantillon, Turgot, Smith, Quesnay, Say, Knight, Weber, } \\
\text { Sombart, Veblen. }\end{array}$ \\
\hline
\end{tabular}

Fuente: Propuesta por Elkjaer (1991) ${ }^{25}$ reformulada por Formaini $(2002)^{57}$ y con agregados nuestros en cursiva.

puede ser o no participe del capital- con base en sus conocimientos respecto a la toma de decisiones, interpretación del mercado, tecnologías, etcétera. Por esta vía se llega a una etapa de capitalismo avanzado en que el capital, fraccionado entre un número amplio de accionista, elige al empresario en función de su capacitación. Este es el caso del empresario profesional o empresario control.

El empresario por una parte, afronta ahora no un riesgo patrimonial, sino un riesgo profesional, es decir, arriesga la continuidad en su puesto. El poder y el prestigio pueden conseguirse haciendo que la empresa aumente de tamaño, gane cuotas de mercado y otras. Por otra se supone que los accionistas o el consejo de administración pueden cambiar en cualquier momento al empresario que no trabaje por sus intereses, incluso una empresa que no esté siendo bien administrada puede ser objeto de absorción por otra. Por ende la influencia de los intereses de los empresarios en la adopción de decisiones en la empresa es un hecho que debe ser tenido en cuenta.

Se produce entonces una importante ruptura en la identidad de los objetivos empresariales: los accionistas persiguen la obtención de unos frutos presentes o futuros de la inversión, mientras que el empresario-profesional busca una continuidad que depende tanto de los accionistas como del crecimiento de la empresa que incremente su poder y le brinde alternativas de cambio hacia otros puesto más atractivos en otras empresas. Esta doble dinámica va a configurar la plasmación de los objetivos de la empresa empeñada en una supervivencia dentro de un contexto competitivo en el que el crecimiento, en un sentido muy amplio, es una garantía de subsistencia. Ahora, las características dominantes del empresario actual son un empresario-profesional, promotor innovador y administrador ${ }^{25}$.

En resumen, se detallan las funciones que históricamente asume el empresario:

\section{El empresario riesgo.}

El empresario actual (aunque no sea propietario) asume un riesgo en cuanto se convierte en el asegurador de las rentas de la empresa y acepta los riesgos de la producción convirtiéndose en el responsable del proceso productivo. Dentro de esta línea encontramos a Walras quién identifica empresa y empresario. La más amplia aplicación de esta idea vendría representada por los autores que opinan que los empresarios son todas aquellas personas que participan en el producto productivo y arriesgan algo. Esta teoría ha tenido numerosas críticas ya que tanto el empresario como el accionista asumen riesgos. Es por esto que no puede hablarse del riesgo como característica única y diferencial que define la función del empresario, su importancia no puede dejar de señalarse.

\section{El empresario capital.}

Esta íntimamente ligado con el empresario riesgo. Empresario capitalista es el empresario que aporta capital. De esta idea participaba Adam Smith, pierde fuerza a medida que la transformación de la sociedad industrial lleva a la distinción entre propietario y empresario, entre capitalista y director de procesos, lo cual desemboca en la idea del empresario como cuarto factor de producción.

\section{Función combinación de factores.}

La idea de que el empresario cumple un papel fundamental como organizador y rector del proceso económico se encuentra más en línea con el pensamiento actual. La función del empresario se entiende en dos vertientes: El empresario es la persona que interpreta el futuro cuanto (riesgo) de la firma (función de previsión y pronóstico) y de acuerdo con su estimación acerca de la expectativas de la misma combina los factores de producción (función dirección) controlando (función de control) que el proceso se realiza de acuerdo con lo por él planificado (función planificación). Aunque pueden hacerse muchas críticas a esta teoría, es la que más se acerca a la idea actual de la figura del empresario. Principal crítica: ser excesivamente vaga y amplia al dejar a los accionistas fuera del concepto de empresario.

\section{Función incertidumbre.}

Según Cantillon la función principal que caracteriza al empresario era la incertidumbre. El beneficio se entiende como la remuneración de la decisión formada en 
condiciones de incertidumbre. Cuando el empresario conoce, en términos de probabilidad, la incertidumbre, se dice que se enfrenta a una situación de riesgo (ganancia o pérdida), ante la que debe actuar de la forma económicamente más racional.

\section{Función innovadora.}

Joseph A. Schumpeter desarrolló el concepto de empresario-innovador, por tanto el interés como el beneficio se derivan del cambio progresivo.

Finalmente, las funciones características del empresario de acuerdo a los autores consultados se agrupan en dos: 1) los que consideran que la función económica del empresario se caracteriza por la asunción del riesgo; 2) los que estiman que la función principal es la directiva y de control del proceso económico.

Director, propietario, dirigente, hombre de negocios, capitalista, burgués, capitán de industria, gerente, coordinador profesional, son aspectos de un mismo actor social que bajo el nombre genérico de «empresario» constituye hoy un sujeto social complejo. A este actor social además hay que añadirle una gran disparidad interna proveniente de la estratificación del capital. En efecto, tal vez existan menos diferencias entre gerentes y accionistas de una empresa que entre pequeños y grandes empresarios. La distancia que separa hoy a las empresas puede estar representada por miles de empleados, por miles de toneladas de producción y por millones de pesos en ventas $\mathrm{y}$ activos.

La falta de consenso sobre la definición de empresario y su función hay que buscarla en el hecho de que todos los autores antes mencionados que intentan elaborar una definición del empresario, se mueven en el marco de las llamadas definiciones esencialistas. La filosofía de la ciencia nos enseña que el esencialismo metodológico, que tiene su origen en Platón y Aristóteles, pero que perdura inconscientemente en la mente de algunos investigadores, pretendía identificar por medio de la intuición la o las características esenciales de un objeto y evidentemente, cada autor considera más esencial y característico un rasgo y otro. ${ }^{41}$ El concepto de empresario recoge a aquella persona que de forma individual o también aquellos órganos de carácter colegiado, que toman las decisiones oportunas para la consecución de objetivos previamente fijados que dependerán de los grupos de interés presentes en las empresas. En las empresas privadas estos grupos de presión están formados por los propietarios o accionistas, los directivos o administradores y los trabajadores.

Se ha visto que el concepto de empresario aparece íntimamente unido al concepto de empresa concebida ésta como realidad socioeconómica. El empresario personaliza la actuación de la empresa siendo la figura representativa que, según sus motivaciones, persigue unos objetivos coherentes con los fines a conseguir por la empresa en un intervalo temporal. En definitiva, se constituye como el órgano individual o colectivo encargado de establecer los objetivos empresariales y la toma de decisiones oportunas para alcanzarlos. Por lo tanto, a la palabra empresario se le pueden unificar, aunque en apariencia, los esquemas teóricos que se han descrito, relativamente distintos y en ocasiones contradictorios. La evolución cronológica del concepto otorga la riqueza de su acumulación.

\section{REFERENCIAS}

${ }^{1}$ Ferguson, J. (1979). Historia de la economía. México: Fondo de Cultura Económica.

${ }^{2}$ Marshall, A. (1957). Principios de Economía. Madrid: Aguilar.

${ }^{3}$ Weber, M. (1979). La ética protestante y el espíritu del capitalismo. México: Premia Editora.

${ }^{4}$ Keynes, J. (1964). The general theory of employment, interest and money. Nueva York.

${ }^{5}$ Robinson, J. V. (1946). La economía de la competencia imperfecta. Madrid: Aguilar.

${ }^{6}$ Brandenburg, F. (1962). Capitalismo, socialismo y empresa: el caso de México. Revista Mexicana de Ciencias Políticas. Núm. 29, VIII, julio-sep.

${ }^{7}$ Arriagada, G. (2004). Los empresarios y la política. Santiago de Chile: LOM Ediciones.

${ }^{8}$ Schumpeter, J. A. (1976). Teoría del desenvolvimiento económico. México: FCE.

${ }^{9}$ Schumpeter J. A. (1978). La teoría económica y la historia empresarial. Ensayo.

${ }^{10}$ Schumpeter, J. A. (1983). Capitalismo, socialismo y democracia. Barcelona: Orbis.

${ }^{11}$ Coase, R. H. (1999, Mayo). La naturaleza de la empresa. Revista Economía Informa. Núm. 277, Fe-UNAM México, 7-20.

12 Valerio, U. S. (1999, Mayo). Los empresarios bajo la lupa historiográfica. Revista Economía Informa. Núm. 277, Fe-UNAM, 44.

${ }^{13}$ Burnham, J. (1967). La revolución de los directores. Buenos Aires: Sudamericana.

${ }^{14}$ Romero M. E. (2003, Marzo). La historia empresarial. Revista Historia Mexicana, Núm. 3, Vol. LII, Colegio de México. ${ }^{6}$

${ }^{15}$ Knight, F. H. (1947). Riesgo, incertidumbre y beneficio. Madrid: Aguilar.

${ }^{16}$ Galbraith, J. K. (1970). El nuevo estado industrial. Barcelona: Ariel.

${ }^{17}$ Mills, W. (1963). La élite del poder. FCE, México, 112-113.

${ }^{18}$ Veblen, T. (1965). Teoría de la empresa de negocios. Buenos Aires: Eudeba.

${ }^{19}$ Ferrarotti, F. (2000, Marzo). El empresario como protagonista en Veblen y Schumpeter. Revista problemas del desarrollo. Núm 120, Vol. 31, México.

${ }^{20}$ Veblen, T. (1995). La Teoría de la clase ociosa. FCE, México, 216-217.

${ }^{21}$ Sombart, W. (1972). El burgués. Madrid: Alianza Universidad.

${ }^{22}$ Sombart, W. (1982). El burgués. Madrid: Alianza Universidad.

${ }^{23}$ Sombart, W. (1946). El apogeo del capitalismo I. FCE, México, 29.

${ }^{24}$ Chandler, D. Jr. (1987). La Mano visible. La revolución en la dirección de la empresa norteamericana. Madrid: Ministerio de Trabajo y Seguridad Social, 15-30.

${ }^{25}$ Elkjaer, J. R. (1991). The entrepreneur in economic theory: an example of the development and Influence of a concept. History of european ideas 13 (6): 805-15.

${ }^{26}$ Bueno, E., Cruz, I., y Durán, J.J. (1990). Economía de la empresa. ISBN 8436802071.

${ }^{27}$ Veciana, J. M. (1998). Origen y evolución del emprendedurismo y la creación de empresas. Diferentes etapas y enfoques a lo largo de su historia. Universidad Autónoma de Barcelona. 